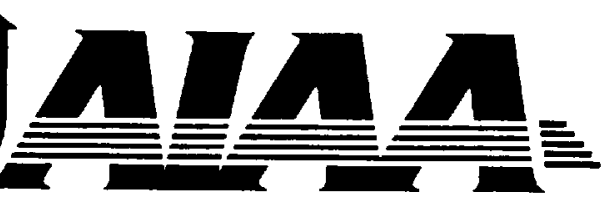

AIAA 96-2412

Development of Semi-Span Model

Test Techniques

William E. Milholen II and Ndaona Chokani

North Carolina State University

Raleigh, NC

Robert J. McGhee

NASA Langley Research Center

Hampton, VA

14th AIAA Applied Aerodynamics Conference June 17-20, 1996 / New Orleans, LA 



\title{
DEVELOPMENT OF SEMI-SPAN MODEL TEST TECHNIQUES
}

\author{
William E. Milholen II * and Ndaona Chokani ${ }^{\dagger}$ \\ North Carolina State University, Raleigh NC 27695 \\ and \\ Robert J. McGhee ${ }^{\ddagger}$ \\ NASA Langley Research Center, Hampton VA 23681
}

\begin{abstract}
$\underline{\text { Abstract }}$
A computational investigation was performed to support the development of a semispan model test capability in the NASA Langley Research Center's National Transonic Facility. This capability is desirable for the testing of advanced subsonic transport aircraft at full-scale Reynolds numbers. A state-of-the-art three-dimensional Navier-Stokes solver was used to examine methods to improve the flow over a semi-span configuration. First, a parametric study is conducted to examine the influence of the stand-off height on the flow over the semispan model. It is found that decreasing the stand-off height, below the maximum fuselage radius, improves the aerodynamic characteristics of the semi-span model. Next, active sidewall boundary layer control techniques are examined. Juncture region blowing jets, upstream tangential blowing, and sidewall suction are found to improve the flow over the aft portion of the semispan model. Both upstream blowing and suction are found to reduce the sidewall boundary layer separation. The resulting near surface streamline patterns are improved, and found to be quite similar to the full-span results. Both techniques however adversely affect the pitching moment coefficient.
\end{abstract}

* Graduate Research Assistant, Department of Mechanical and Aerospace Engineering. Presently NRC Research Associate, NASA Langley Research Center, Student Member AIAA.

${ }^{\dagger}$ Associate Professor, Department of Mechanical and Aerospace Engineering, Member AIAA.

$₫$ Research Scientist, Aerodynamics Division. Copyright (C) 1996 American Institute of Aeronautics and Astronautics Inc. All rights reserved.

\section{Nomenclature}

$\mathrm{A}_{j} \quad$ cross sectional area of blowing jet

$\mathrm{C}_{\mathrm{D}} \quad$ drag coefficient

$\mathrm{C}_{\mathrm{L}} \quad$ lift coefficient

$\mathrm{C}_{\mathrm{M}} \quad$ pitching moment coefficient

$\mathrm{C}_{\mathrm{p}} \quad$ surface static pressure coefficient

$\Delta C_{p} \quad\left(C_{p}\right)_{s s}-\left(C_{p}\right)_{f s}$

$\mathrm{C}_{\mathrm{q}} \quad$ surface transpiration coefficient, $\frac{(\rho \mathrm{U})_{w}}{(\rho \mathrm{U})_{\infty}}$

$\mathrm{C}_{\mu} \quad$ blowing coefficient, $\frac{(\dot{\mathrm{m} U})_{\mathrm{j}}+\left(\mathrm{P}_{\mathrm{j}}-\mathrm{P}_{1}\right) \mathrm{A}_{\mathrm{j}}}{\mathrm{q}_{\infty} \mathrm{S}}$

c local chord length

h stand-off height

L fuselage length, 74.5in.

M Mach number

$\dot{\text { m }}$ mass flow rate

$P \quad$ static pressure

q dynamic pressure

Re Reynolds number based on mean geometric chord

S semi-span wing reference area

$\mathrm{U}$ total velocity magnitude

$\mathrm{x}, \mathrm{y}, \mathrm{z}$ Cartesian coordinate system

$\mathrm{x} / \mathrm{c}$ nondimensional chord fraction

$\alpha \quad$ angle-of-attack, deg.

$\delta^{*} \quad$ tunnel empty sidewall boundary layer displacement thickness, $0.30 \mathrm{in}$. at $x / L=0.50$

$\eta \quad$ nondimensional semispan fraction

$\rho$ density

Subscripts

fs full-span

j jet value

1 local value

ss semi-span

w wall value

$\infty$ free stream value 


\section{Introduction}

Historically, transport aircraft have been tested in ground test facilities at Reynolds numbers significantly lower than flight Reynolds numbers. The extrapolation of low Reynolds number data to flight conditions can however be problematic due to nonlinear variations ${ }^{1}$. This behavior significantly increases the risk of relying on low Reynolds number data. Thus, it is highly desirable to design and test advanced subsonic transport configurations at flight Reynolds numbers. To meet this challenge, a semi-span model test technique has been proposed for the NASA Langley Research Center's National Transonic Facility (NTF).

In the semi-span test technique the semispan model is mounted on the test section sidewall, in contrast to the use of a full-span model used in conventional wind tunnel testing, Figure 1. The primary advantage of semi-span model testing is the increased Reynolds number capability due to the larger model size. The increased model size also allows for more accurate positioning of the model components, improved model fidelity, and increased model stiffness; all these features improve the data quality ${ }^{2}$. In spite of these advantages, the use of a semi-span model introduces additional difficulties which must be addressed in the semi-span test procedure. These difficulties include the effects of the semi-span model mounting, which are considered in the present work, and the effects of increased wind tunnel wall interference due to the increased model size ${ }^{3}$. The present work is part of an integrated computational ${ }^{4}$ and experimental ${ }^{5}$ research program currently in progress at NASA Langley Research Center.

In a previous computational study ${ }^{4}$, the first two authors examined the aerodynamic characteristics of both a full-span and semi-span model. As shown in Figure 2, the lift and pitching moment coefficients of the semi-span model differed considerably from those of the full-span model. A detailed examination of the computational results revealed that the semi-span model experienced increased flow acceleration over its entire upper surface. In addition, an increased cross flow on the inboard portion of the upper wing surface was observed. Furthermore, a strong interaction between the sidewall boundary layer and semi-span model mounting was observed. The good agreement between the computational results ${ }^{4}$ and experimental data $^{6}$ gave confidence that the computational method may be reliably used to complement further experimental studies.

The objective of the present numerical study is to examine methods to alleviate the adverse effects of the semi-span model mounting. A Navier-Stokes solver is employed to compute the flow over various semi-span configurations. First, a parametric study is conducted to examine the influence of the stand-off height on the flow over the semi-span model. Next, the flow solver is used to examine methods to control the sidewall boundary layer. The methods examined are: juncture region blowing jets ${ }^{7}$; upstream tangential blowing ${ }^{8}$; and sidewall suction ${ }^{7,9}$. Although these boundary layer control techniques have been used in other applications, there is little knowledge concerning their use in semi-span model testing. These computations are compared to the previous semi-span computations without control, to assess the control effectiveness.

\section{Stand-off Mounting Geometries}

The present semi-span test configuration in the NTF uses a non-metric stand-off to support the model away from the wind-tunnel sidewall. The profile shape of the stand-off is identical to that of the full-span fuselage symmetry plane, and presently has a height of 4.50 inches, or $h / \delta^{*}$ $=15.0$. Three additional stand-off geometries were generated, with $h / \delta^{*}$ values of $1.0,2.0$, and 5.0. Figure 3 shows a frontal view of the four stand-off geometries. For reference, the fuselage radius ahead of the wing is approximately 4.30 inches.

\section{Boundary Layer Control Techniques}

The first sidewall boundary layer control technique examined is juncture region blowing jets. Figure 4 shows the locations of the blowing 
jets. The jets had a nominal diameter of 0.25 inches, and were located in the juncture of the stand-off and sidewall. Following the approach in Reference 7 , the two upstream jets were positioned to coincide with the streamwise adverse pressure gradients. The two aft jets were positioned to minimize the separation downstream of the stand-off. The jets were aligned to blow tangent to the stand-off shape.

The second sidewall boundary layer control technique examined is upstream tangential blowing. A blowing slot was located a distance of $L / 4$ upstream of the model. The slot width, perpendicular to the $x$-axis, was approximately $0.60 \mathrm{~L}$. The slot height normal to the windtunnel sidewall was approximately $1 / 8 \mathrm{inch}$. The injected flow was tangent to both the sidewall and the approaching freestream.

The third sidewall boundary layer control technique examined is sidewall suction. A segmented suction system comprised of two regions was developed. In the first region, suction is confined to the nose region of the model. This semicircular region extended upstream of the model a distance of approximately .12L. The second region is an extension of the first over the entire juncture region. The second region extended outward from the stand-off an average distance of . $10 L$.

\section{Numerical Procedure}

\section{Computational Code}

The code used for the computational study is TLNS3D-MB. The code solves the timedependent, three-dimensional, thin-layer compressible Navier-Stokes equations on blockstructured, body-fitted grids. The equations are discretized in a central difference finite volume formulation, and integrated using an explicit second-order accurate Runge-Kutta timestepping scheme. Multigrid, grid sequencing, and local time stepping techniques are used to accelerate the convergence to steady state. Fully turbulent flow was simulated with both the Baldwin-Lomax and Spalart-Allmaras turbulence models. Additional details of the code are found in Reference 10. The adequacy of the code for examining the low-speed flow over the full-span and semi-span models is described in Reference 11.

\section{Grid Generation}

Figure 5 shows a partial view of the $\mathrm{C}-\mathrm{O}$ grid topology used to represent the original NTF semi-span configuration ${ }^{4}$. The multiblock structured grids were generated using GRIDGEN ${ }^{12}$. Alternate stand-off heights are efficiently examined by replacing the grid blocks representing the stand-off. The full-span grid is obtained by simply removing the stand-off geometry. Grid points are clustered in the streamwise, normal, and spanwise directions to resolve the expected large flow gradients. The far-field boundaries are located six semi-span lengths from the model, which corresponds to approximately 18 root chord lengths.

\section{Boundary Conditions}

The boundary conditions used for the fullspan and semi-span computations are as follows. The far-field outer boundary is treated using characteristic boundary conditions. The properties at the downstream boundary are obtained using a zeroth-order extrapolation from the interior. The fuselage and wing surfaces are treated as adiabatic, no-slip, zero normal pressure gradient surfaces. For the semi-span configuration, the stand-off surface is also treated as a no-slip surface. It should however be noted that this surface is not included in the force and moment calculations since the stand-off is non-metric in the experiment. For the full-span computations, symmetry conditions are used at the root plane, resulting in a "free-air" simulation. For the semispan computations, the root plane is treated as a no-slip surface in order to simulate the windtunnel sidewall boundary layer. To simulate a blowing jet or slot, a grid block boundary is first introduced at the prescribed location. The blowing is then simulated as an inflow boundary condition with specified Mach number, stagnation pressure, stagnation temperature, and flow angle. The suction is simulated by specifying a constant normal velocity over the prescribed area. The implementation of the boundary conditions are described in detail in Reference 13. 


\section{Results and Discussion}

A grid refinement study was conducted for the full-span configuration, simulating full turbulent flow using the Baldwin-Lomax turbulence model. Figure $6 \mathrm{a}$ shows a representative comparison of the computational results with experimental data for $\mathrm{M}_{\infty}=.20, \alpha=4.43^{\circ}$, and $\operatorname{Re}=4.2 \times 10^{6}$. The grid dimensions, such as $241 \times 65 \times 81$, represent the number of grid points in the streamwise, normal, and spanwise directions respectively. It is seen that refinement of the grid improves the agreement with experimental data, particularly in the leading edge region. Further streamwise refinement up to 481 points was examined; the results obtained were identical within plotting accuracy to those obtained with the $241 \times 65 \times 81$ grid. Thus the $241 \times 65 \times 81$ grid was used for the full-span computations. For this grid, the wing surface grid dimensions were $145 \times 61$. The typical values of $y^{+}$for the first grid point off the wing surface and fuselage were in the range of 1.0-5.0. Figure $6 \mathrm{~b}$ examines the influence of the turbulence model on the wing pressure distribution. The results obtained using the Spalart-Allmaras turbulence model are in better agreement with the experimental data. Similar improvements were observed across the entire span of the wing ${ }^{13}$, and the Spalart-Allmaras turbulence model was used for all subsequent computations. A grid refinement study was also conducted for the semispan configuration. This study indicated that 33 points were adequate to resolve the sidewall boundary layer. The resulting dimensions for the semi-span grid were $241 \times 65 \times 113$.

\section{Effect of Stand-off Height}

The effect of the stand-off height on the lift and pitching moment coefficients at an angle-ofattack of $8.58^{\circ}$ is shown in Figure 7 . The fullspan values are also shown for comparison. The stand-off height has a strong influence on the semi-span model's aerodynamic coefficients. As the stand-off height is decreased from $15 \delta^{*}$ to $2 \delta^{*}$, the agreement with the full-span values improves significantly. The shortest stand-off, $h=$ $\delta^{*}$, underpredicts the full-span values. Extrapolation of the results shows that decreasing the stand-off height below $\delta^{*}$ would result in poorer agreement with the full-span values.

Figure 8 compares the differential pressure distributions for all stand-off heights, at three spanwise stations. With the original stand-off, $h$ $=15 \delta^{*}$, the semi-span model experiences significant flow acceleration over the entire upper wing surface. As the height is decreased, the induced flow acceleration over the entire upper surface of the wing decreases dramatically. The $2 \delta^{*}$ standoff shows very good agreement with the full-span pressure distribution, with the $\Delta C_{p}$ values being quite small over the aft $75 \%$ of the wing. The $1 \delta^{*}$ stand-off case has positive $\Delta C_{p}$ values, indicating that the flow is decelerated as compared to the full-span configuration.

The pressure distribution along the fuselage centerline for each stand-off height is compared to the full-span result in Figure 9. Upstream of the wing, the stand-off height has a strong effect. Overall, the agreement between the semispan and full-span computations improves as the stand-off height is decreased. The $2 \delta^{*}$ stand-off gives the best agreement with the full-span result. It is pertinent to point out that there were no spanwise pressure gradients on the stand-offs. Thus, the results in Figure 9 also indicate that the lift generated by the stand-off decreases with the stand-off height.

The influence of the stand-off height on the upper wing surface streamline pattern is examined in Figure 10, where the full-span result is compared to the semi-span results with standoff heights of $15 \delta^{*}$ and $2 \delta^{*}$. On the outboard portion of the wing the streamline patterns are quite similar. On the inboard portion of the semi-span wing, the cross flow is observed to decrease with the stand-off height. The $2 \delta^{*}$ result is in good agreement with the full-span result. In addition, the $2 \delta^{*}$ stand-off was found to dramatically improve the stall characteristics of the semi-span model in comparison to the original configuration $^{13}$. The root plane streamline patterns in the nose region of the same configurations are compared in Figure 11. The extent of the sidewall boundary layer separation decreases 
with the stand-off height; however, even for the $2 \delta^{*}$ case the separation is not eliminated.

The performance of the $2 \delta^{*}$ stand-off was further examined at angles-of-attack of $4.43^{\circ}$ and $12.55^{\circ}$. The lift and pitching moment coefficients are compared to those of the full-span and $15 \delta^{*}$ semi-span case in Figure 12. The $2 \delta^{*}$ standoff shows marked improvements over the original $15 \delta^{*}$ stand-off results. The pitching moment coefficients compare very favorably with those of the full-span, but the lift coefficients are still slightly offset. Although the $2 \delta^{*}$ stand-off greatly improves the aerodynamic characteristics of the semi-span model, it is evident that further steps must be taken to minimize the influence of the sidewall boundary layer. In the subsequent sections, the effectiveness of the boundary layer control techniques are examined.

\section{Effect of Boundary Layer Control Techniques}

To examine the effect of the various sidewall boundary layer control techniques, the $2 \delta^{*}$ stand-off geometry was used, and the angle-ofattack was fixed at $12.55^{\circ}$.

\section{Juncture Region Blowing Jets}

The effect of the blowing jets on the inboard differential wing pressure distributions is shown in Figure 13. The first blowing case, $\mathrm{C}_{\mu}$ $=0.008$, simulates a choked condition with an exit Mach number of unity. The second case, $\mathrm{C}_{\mu}=0.002$, simulates an exit Mach number of 0.50 . The $\mathrm{C}_{\mu}$ values characterize the mass flow rate for each individual jet, and not the total mass flow rate. With the addition of blowing, the $\Delta C_{p}$ values on the inboard upper wing surface become more negative, which indicates a slight flow acceleration. The blowing jets were thus observed to have a slight effect on the spanwise load distribution ${ }^{13}$. In addition, the blowing jets did not significantly alter the pressure distribution along the fuselage centerline ${ }^{13}$.

The influence of the blowing jets on the upper surface fuselage streamline patterns is shown in Figure 14. With no blowing, the flow adjacent to the sidewall crosses the fuselage centerline, graphically demonstrating the loss of symmetry. The addition of the blowing jets dramatically improves the streamline pattern. For the choked simulation, $\mathrm{C}_{\mu}=0.008$, only the flow adjacent to the centerline migrates onto the fuselage. As the blowing rate is decreased, the spanwise migration increases slightly. For this reason, even lower blowing rates were not examined. It should be noted that the upper wing surface streamline patterns for both blowing rates were identical to the no blowing case shown in Figure 10c.

The blowing jets were found to have no influence on the separation of the sidewall boundary layer. The blowing jets have however, improved the streamline pattern in the aft region of the model as shown in Figure 15. With no blowing, separation occurs on the aft portion of the stand-off, with the resulting streamline pattern being in sharp contrast to the full-span result. The application of the blowing reenergizes the flow adjacent to the stand-off, allowing the flow to remain attached. The resulting streamline pattern is quite similar to the full-span result. Similar improvements were observed with the lower blowing rate $^{13}$. Further studies were conducted to examine the influence of additional jets in the lower juncture region. The results obtained for both blowing rates were identical to within plotting accuracy of those discussed above $^{13}$.

The juncture region blowing jets were successfully demonstrated in a recent experimental investigation in the $14 \times 22$ Foot Subsonic Tunnel at NASA Langley Research Center. The blowing jets were found to significantly improve the high angle-of-attack performance, providing results quite similar to those of the corresponding full-span model. These results are discussed in Reference 5.

\section{Upstream Tangential Blowing}

The effect of the upstream tangential blowing on the root plane streamline pattern is shown in Figure 16. The blowing case, $\mathrm{C}_{\mu}=1.027$, simulates a choked condition with an exit Mach number of unity. The vertical line shows the lo- 
cation of the simulated blowing slot. The blowing has weakened the horseshoe vortex, with the resulting streamline pattern being quite similar to the full-span result. A second blowing case, $\mathrm{C}_{\mu}=0.257$, which represents an exit Mach number of 0.50 was also examined. The resulting sidewall streamline pattern was nearly identical to that shown in Figure 16c. Finally, a blowing rate of $\mathrm{C}_{\mu}=0.041$, which represented an exit Mach number of 0.20 was examined. This blowing rate had little influence on the sidewall streamline pattern, and is thus considered a lower bound for effective blowing.

The influence of the upstream tangential blowing on the upper surface fuselage streamline pattern is shown in Figure 17. The influence of the upstream blowing is not limited to the forward portion of the semi-span model. The blowing has a strong effect on the aft fuselage streamline pattern, decreasing the spanwise migration. As the blowing rate is decreased, the spanwise migration increases ${ }^{13}$. It should be noted that for the two highest blowing rates, the computations predict attached flow over the aft portion of the stand-off geometry. In an attempt to further improve the fuselage streamline pattern, the juncture blowing jets were also included in the blowing simulation. The results indicated that in the presence of the upstream blowing, the juncture blowing jets have little effect ${ }^{13}$.

The influence of the upstream blowing on the semi-span lift and pitching moment coefficients is shown in Figure 18. Here, both coefficients are plotted versus the blowing coefficient. For comparison, the full-span values are also shown. With the addition of blowing, the lift on the semi-span model increases. As the blowing rate is increased, the lift coefficient remains fairly constant. In practical applications, such a shift may not affect the overall data quality. The variation of the pitching moment coefficient however, is of concern. Even low blowing rates significantly increase the pitching moment coefficient. A comparison of the wing and fuselage pressure distributions revealed that the large variations in the total pitching moment coefficient are due largely to the fuselage, and not the wing ${ }^{13}$. The upstream blowing significantly accelerates the flow over the forward portion of the fuselage. Since the upstream blowing had minimal effect on the wing pressure distribution, it would be anticipated that incremental shifts in the total pitching moment coefficient due to a wing mounted control surface would still be accurate.

\section{Sidewall Suction}

The effect of sidewall suction on the root plane streamline pattern is examined in Figure 19. For comparison, both the full-span and original semi-span results are shown. First, a parametric study was conducted to examine the influence of suction in the first region ${ }^{13}$. The results of this study are shown in Figure 19c. The highest suction rate examined, $\mathrm{C}_{\mathrm{q}}(1)=-.020$, has weakened the horseshoe vortex. The streamline pattern in the nose region has improved dramatically, and is quite similar to the full-span result. Downstream of the nose however, the streamline pattern is quite similar to the original semi-span result. Thus, a parametric study was conducted to examine the influence of suction in the second region ${ }^{13}$. The results of this study are shown in Figure 19d. A significantly lower suction rate, $\mathrm{C}_{\mathbf{q}}(2)=-.005$, markedly improves the streamline pattern. In addition, the flow over the aft portion of the stand-off remains attached. The resulting streamline pattern is quite similar to the full-span result. The sidewall suction was observed to have no affect on the wing streamline pattern.

The influence of the sidewall suction on the semi-span lift and pitching moment coefficients is shown in Figure 20, where both coefficients are plotted versus the suction coefficient. The full-span values are again shown for comparison. Suction in the first region alone, $C_{q}(2)=0.00$, has little effect on the aerodynamic coefficients of the semi-span model. The addition of suction in the second region shifts both curves upward. The increase in the lift coefficient is small, while the increase in the pitching moment is noticeable. Even though the coefficients have increased, their variation with $\mathrm{C}_{\mathbf{q}}$ is minimal, 
which is quite encouraging. The sidewall suction was found to slightly increase the inboard wing loading ${ }^{13}$.

\section{Conclusions}

A computational investigation was performed to support the development of a semispan model test capability in the NASA Langley Research Center's National Transonic Facility. This capability is desirable for the testing of advanced subsonic transport aircraft at full-scale Reynolds numbers. A three-dimensional NavierStokes solver was used to examine methods to improve the flow over a semi-span configuration.

The aerodynamic characteristics of the semi-span configuration can be improved by decreasing the stand-off height. A stand-off height equal to twice the tunnel-empty sidewall boundary layer displacement thickness was found to best replicate the characteristics of the full-span configuration. However, the stand-off height had little effect on the separation of the sidewall boundary layer.

Blowing jets placed in the sidewall/standoff juncture region improved the flow over the aft portion of the semi-span model. The resulting near surface streamline patterns were quite similar to the full-span results. The blowing jets had little adverse effect on the semi-span force and moment coefficients.

Upstream tangential blowing and sidewall suction were found to be effective in minimizing the separation of the sidewall boundary layer. The horseshoe vortex was weakened, and the resulting near surface streamline patterns were seen to be similar to the full-span results. Both techniques however adversely affected the pitching moment coefficient.

\section{Acknowledgements}

The research was supported by Cooperative Agreement NCC1-169 between North Carolina State University and the Research Facilities Branch at NASA Langley Research Center. The technical monitor was L. Elwood Putnam, and the authors acknowledge his support and encouragement. The authors are also grateful to Jerry C. South, and all members of the Semispan Test Techniques Research Team, for many useful discussions. The computations were performed on the Numerical Aerodynamic Simulation Facility's Cray C-90.

\section{References}

${ }^{1}$ Mack, M.D. and McMasters, J.H. , "High Reynolds Number Testing in Support of Transport Airplane Development (Invited Paper)," AIAA. Paper 92-3982, July 1992.

${ }^{2}$ Goldhammer, M.I. and Steinle Jr., F.W. , "Design and Validation of Advanced Transonic Wings Using CFD and Very High Reynolds Number Wind Tunnel Testing," Proceedings of the $17^{\text {th }}$ International Council of the Aeronautical Sciences, Paper 90-2.6.2, Sept. 1990, pp. 1028-1042.

${ }^{3}$ Ulbrich, N. and Steinle, F.W., Jr., "Semispan Model Wall Interference Prediction Based on the Wall Signature Method," AIAA Paper 95-0793, Jan. 1995.

${ }^{4}$ Milholen, W.E., II and Chokani, N., "Computational Analysis of Semi-Span Test Techniques", AIAA Paper 95-2290, June 1995.

${ }^{5}$ Gatlin, G.M. and McGhee, R.J., "Study of Semi-Span Model Testing Techniques", AIAA Paper 96-2386, June 1996.

${ }^{6}$ Morgan Jr.,H.L., "Model Geometry Description and Pressure Distribution Data From Tests of EET High-Lift Research Model Equipped with Full-Span and Part-Span Flaps," NASA TM 80048, Feb. 1979.

${ }^{7}$ Paschal, K., Goodman, W., McGhee, R., Walker, B., and Wilcox, P.A., "Evaluation of Tunnel Sidewall Boundary-Layer-Control Systems for High-Lift Airfoil Testing”, AIAA Paper 91-3243, Sept. 1991.

${ }^{8}$ Earnshaw, P.B., Green, A.R., Hardy, B.C. and Jelly, A.H., "A Study of the Use of Half-Models in High-Lift Wind-Tunnel Testing," AGARD CP515, Oct. 1992, pp. 20.1-20.9. 
${ }^{9}$ Philips, D.B, Cimbala, J.M., and Treaster, A.L., "Suppression of the Wing-Body Junction Vortex by Body Surface Suction", Journal of Aircraft, Vol. 29, no. 1, pp. 118-122, 1992.

${ }^{10}$ Vatsa, V.N., Sanetrik, M.D., and Parlette, E.B., "Development of a Flexible and Efficient Multigrid-Based Multiblock Flow Solver," AIAA Paper 93-0677, Jan. 1993.

${ }^{11}$ Milholen, W.E., II and Chokani, N., "A Comparison of Three-Dimensional Compressible Navier-Stokes Codes at Low Mach Numbers", AIAA Paper 95-0767, Jan. 1995.

${ }^{12}$ Steinbrenner, J.P. and Chawner, J.R., "Incorporation of a Hierarchical Grid Component Structure into GRIDGEN," AIAA Paper 93-0429, Jan. 1993.

${ }^{13}$ Milholen, W.E., II and Chokani, N., "Computational Analysis of Semi-Span Model Test Techniques," NASA CR-4709, March 1996.

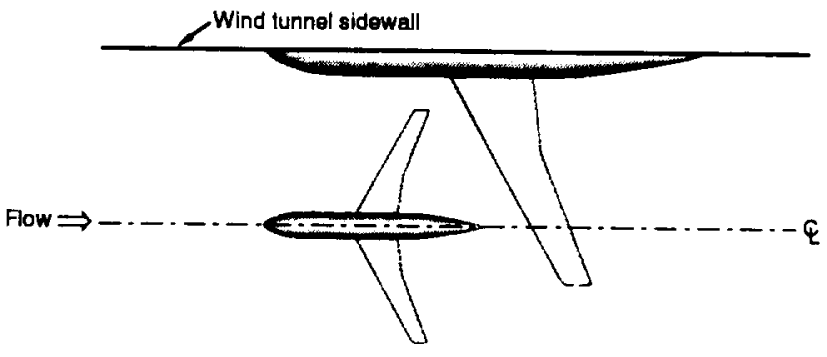

Figure 1: Comparison of full-span and semispan models.
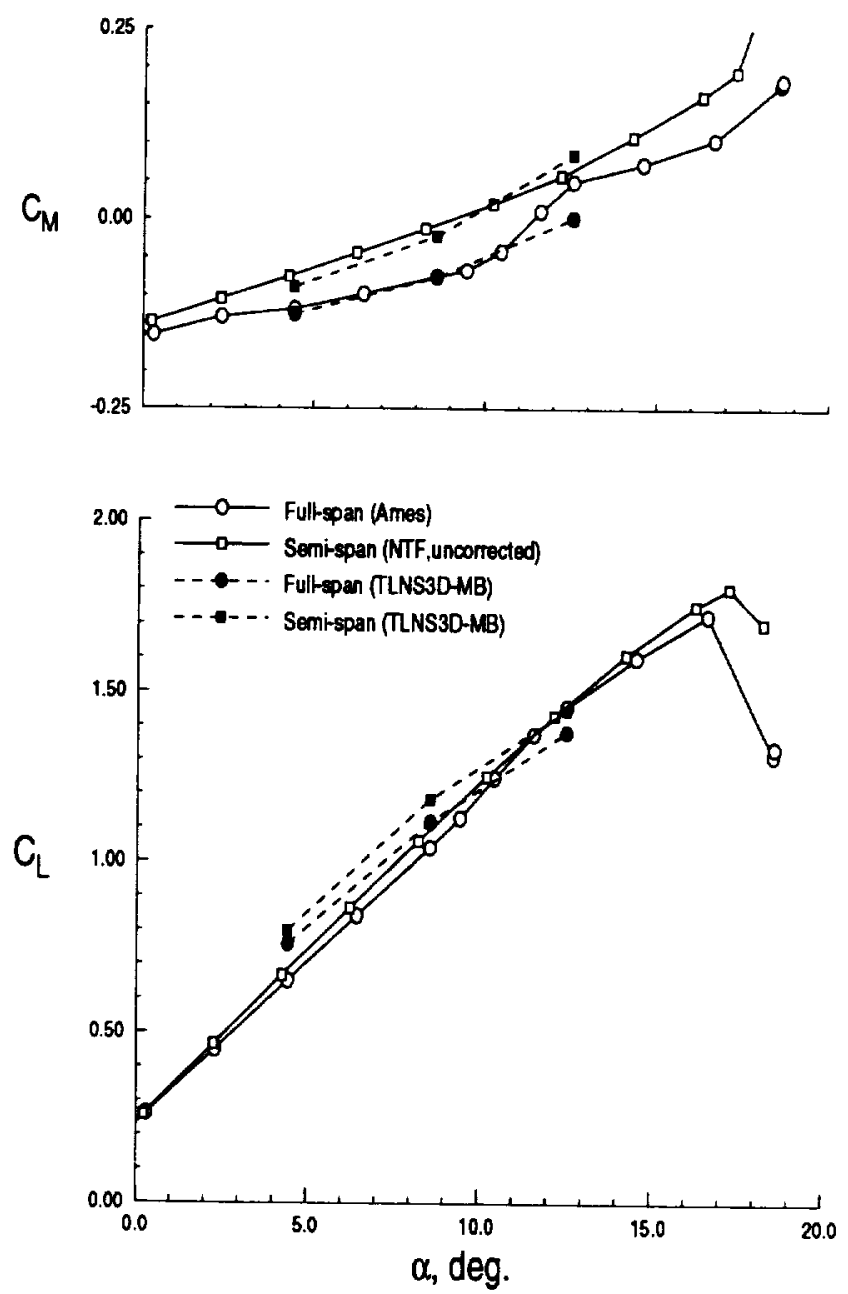

Figure 2: Comparison of full-span and semispan lift and pitching moment coefficients $\left(\mathrm{M}_{\infty}=.20, \mathrm{Re}=4.20 \times 10^{6}\right)$. 

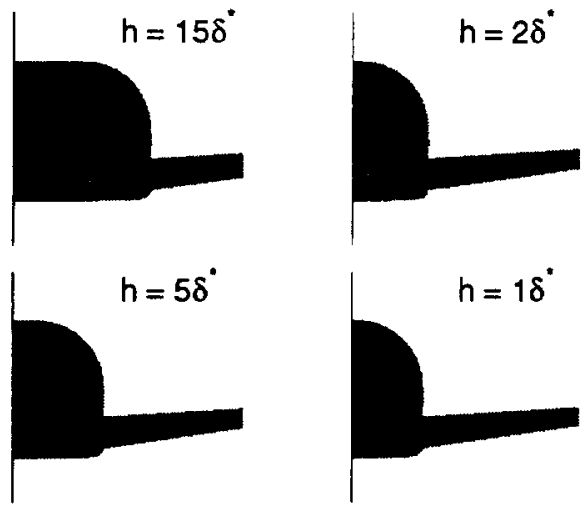

Figure 3: Frontal view of various stand-off heights.

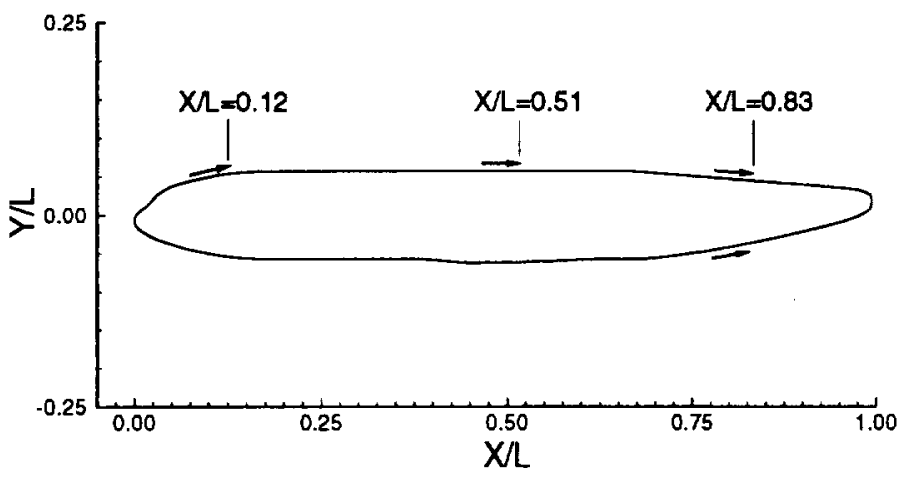

Figure 4: Location of juncture region blowing jets.

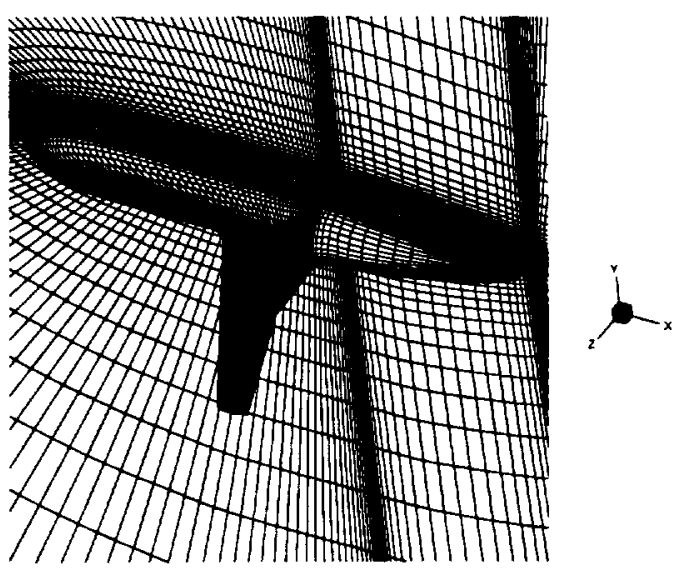

Figure 5: Partial view of semi-span C-O grid topology.

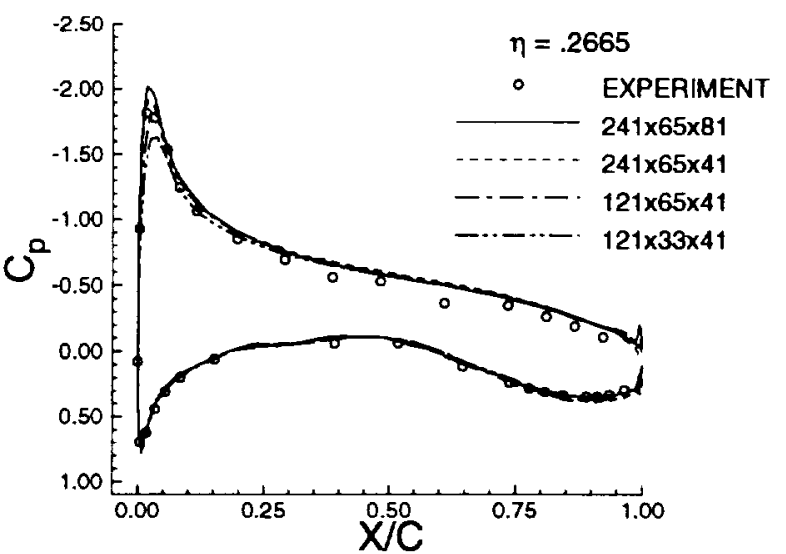

a) influence of grid refinement

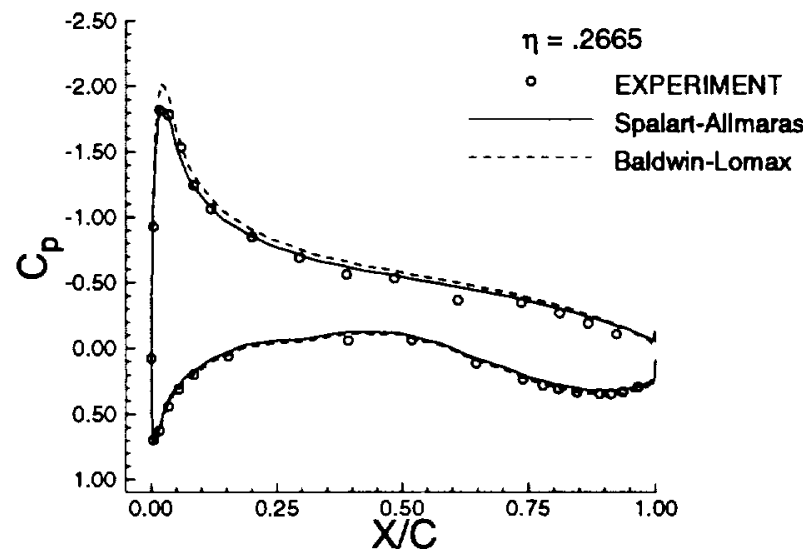

b) influence of turbulence model

Figure 6: Comparison of computed and experimental full-span wing pressure distributions $\left(\mathrm{M}_{\infty}=0.20, \alpha=4.43^{\circ}\right.$, $\left.\operatorname{Re}=4.20 \times 10^{6}\right)$.

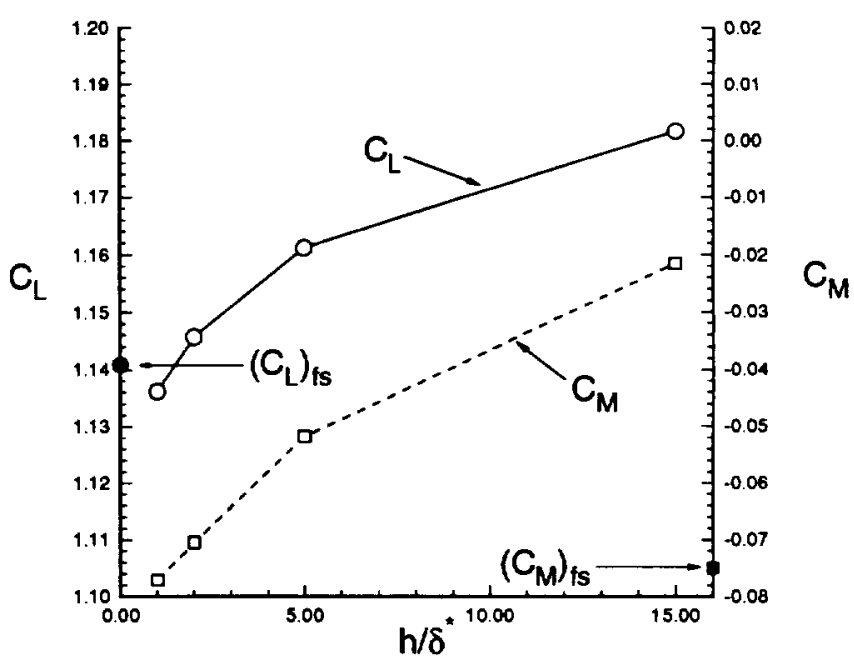

Figure 7: Influence of stand-off height on lift and pitching moment coefficients $\left(\mathrm{M}_{\infty}=0.20, \alpha=8.58^{\circ}, \operatorname{Re}=4.20 \times 10^{6}\right)$. 

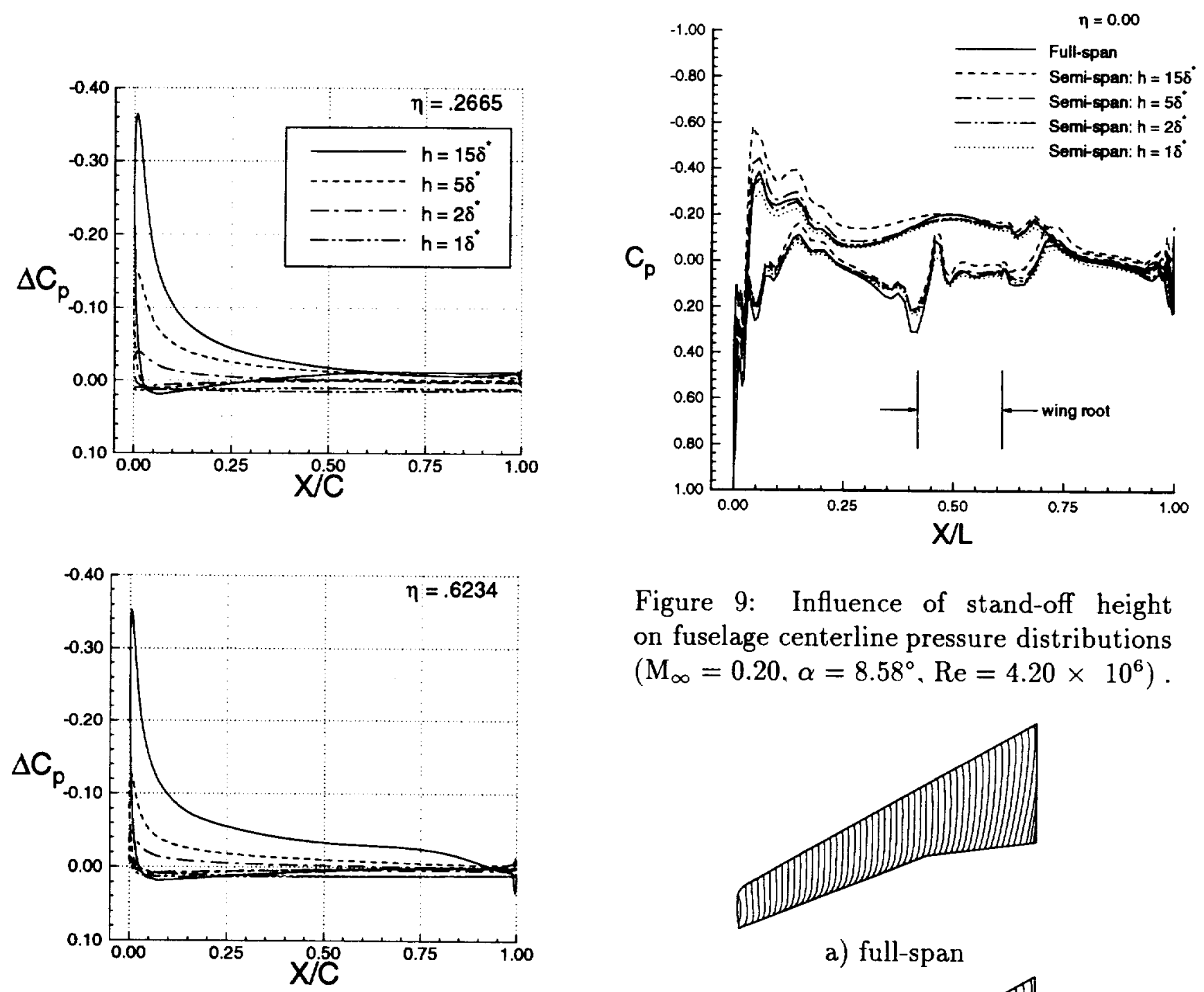

Figure 9: Influence of stand-off height on fuselage centerline pressure distributions $\left(\mathrm{M}_{\infty}=0.20, \alpha=8.58^{\circ}, \mathrm{Re}=4.20 \times 10^{6}\right)$.

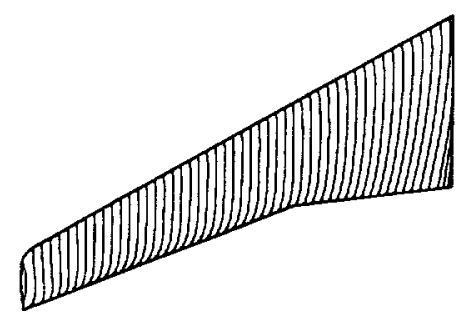

a) full-span

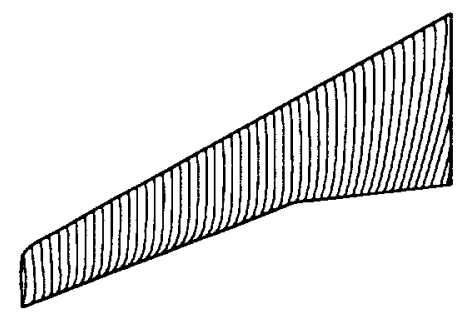

b) semi-span: $\mathrm{h}=15 \delta^{*}$

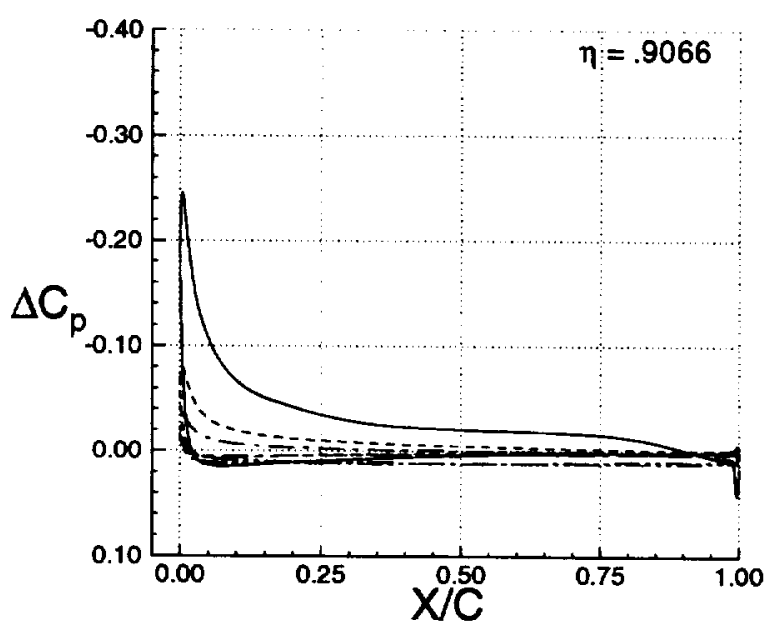

Figure 8: Influence of stand-off height on differential wing pressure distributions $\left(\mathrm{M}_{\infty}=0.20, \alpha=8.58^{\circ}, \operatorname{Re}=4.20 \times 10^{6}\right)$. 


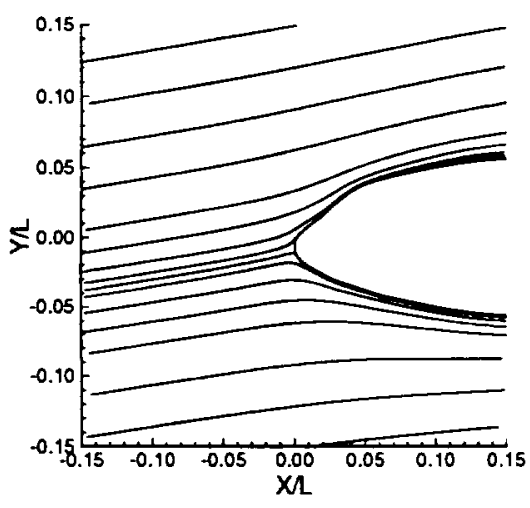

a) full-span

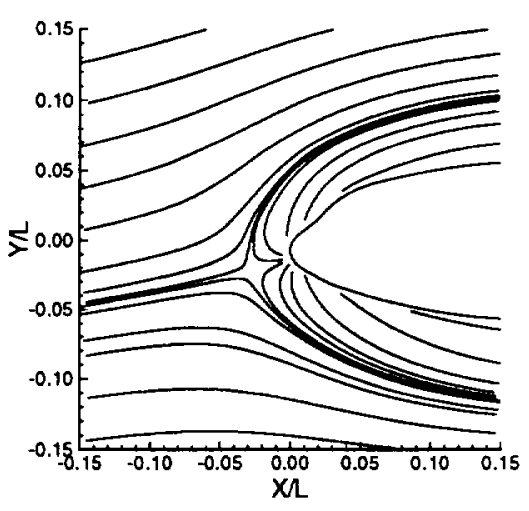

b) semi-span: $\mathrm{h}=15 \delta^{*}$

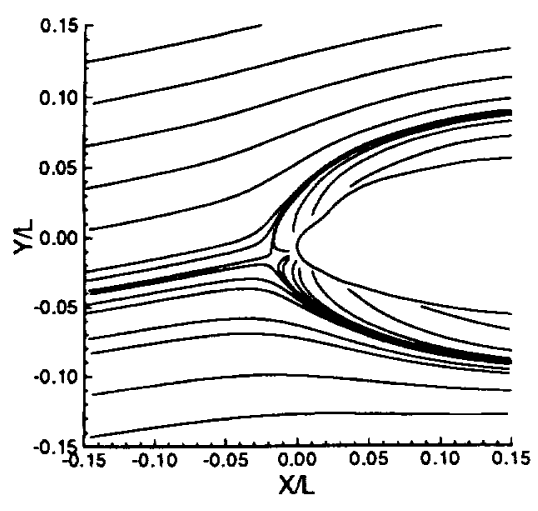

c) semi-span: $h=2 \delta^{*}$

Figure 11: Influence of stand-off height on root plane streamline patterns in nose region $\left(\mathrm{M}_{\infty}=0.20, \alpha=8.58^{\circ}, \operatorname{Re}=4.20 \times 10^{6}\right)$.
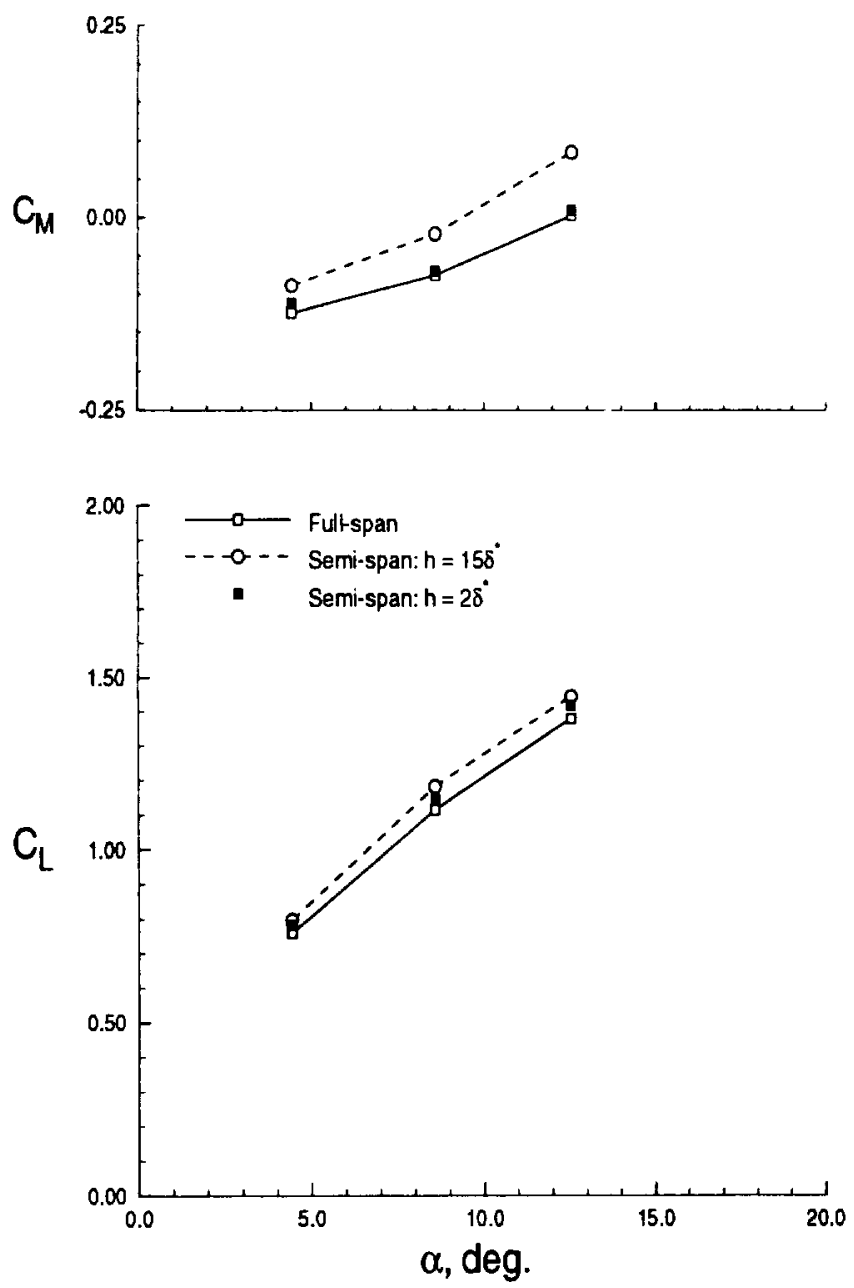

Figure 12: Influence of stand-off height on semi-span lift and pitching moment coefficients $\left(\mathrm{M}_{\infty}=.20, \mathrm{Re}=4.20 \times 10^{6}\right)$.
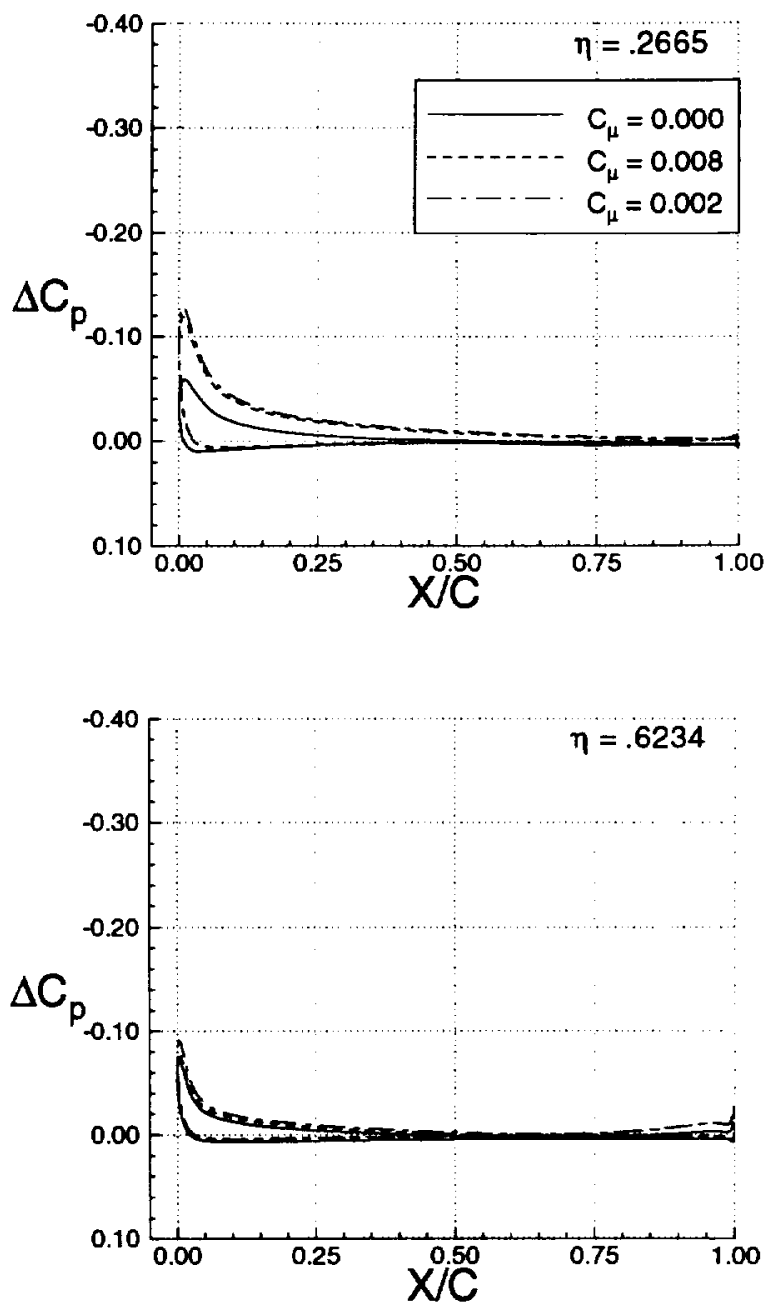

Figure 13: Influence of juncture blowing jets on differential wing pressure distributions $\left(\mathrm{M}_{\infty}=0.20, \alpha=12.55^{\circ}, \operatorname{Re}=4.20 \times 10^{6}\right)$. 


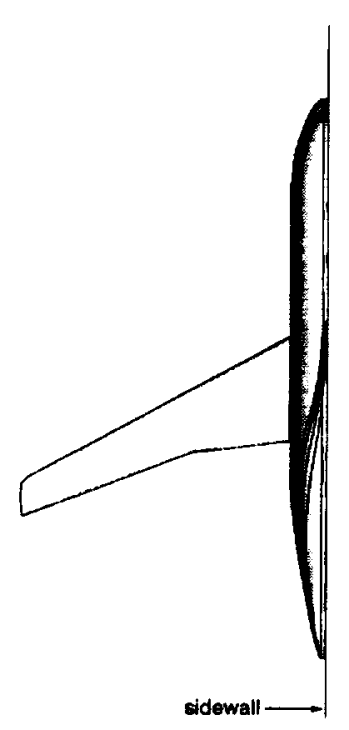

a) $\mathrm{C}_{\mu}=0.000$

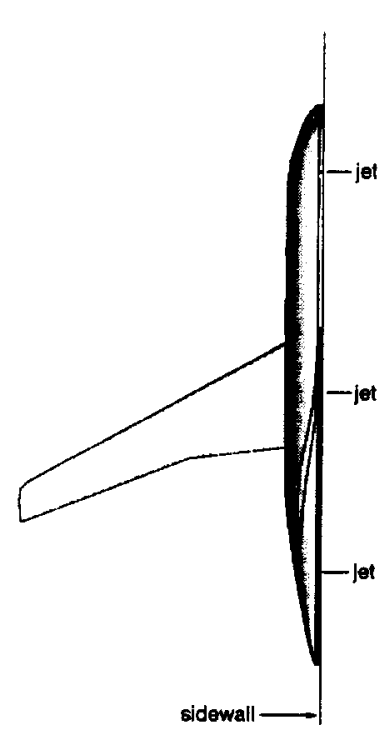

b) $\mathrm{C}_{\mu}=0.008$

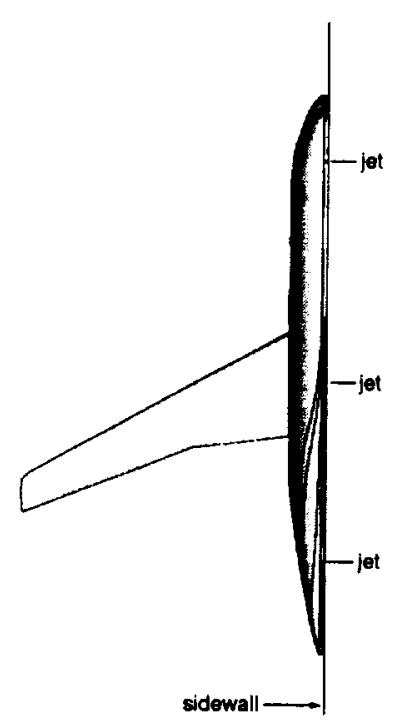

c) $\mathrm{C}_{\mu}=0.002$

Figure 14: Influence of juncture blowing jets on semi-span upper fuselage streamline patterns $\left(\mathrm{M}_{\infty}=0.20, \alpha=12.55^{\circ}, \mathrm{Re}=4.20 \times 10^{6}\right)$.

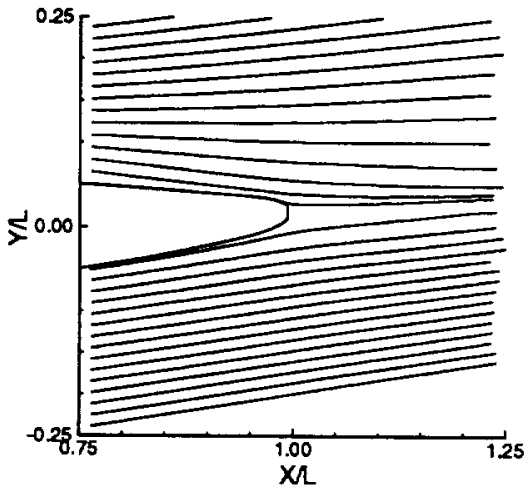

a) full-span

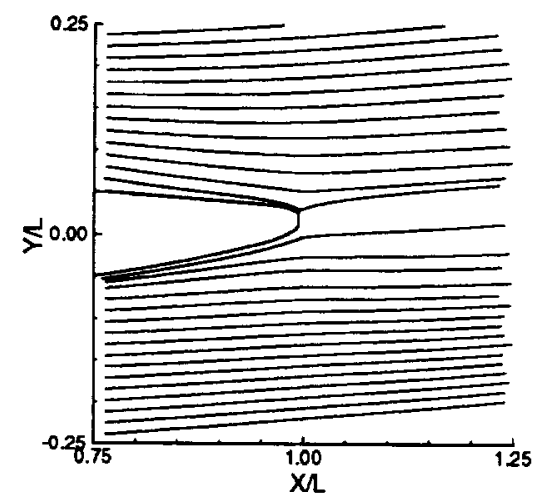

b) semi-span: $\mathrm{C}_{\mu}=0.000$

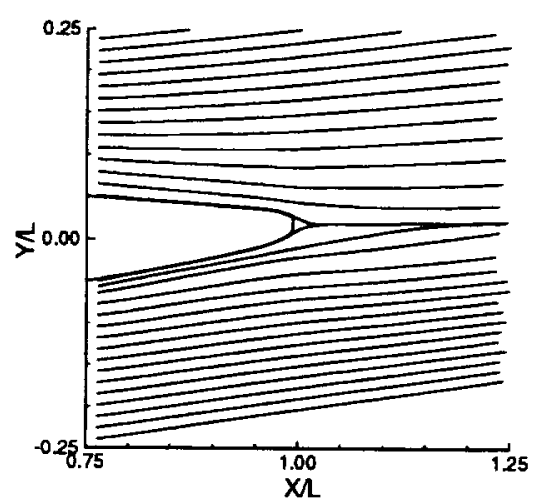

c) semi-span: $\mathrm{C}_{\mu}=0.008$

Figure 15: Influence of juncture blowing jets on aft root plane streamline patterns $\left(\mathrm{M}_{\infty}=0.20, \alpha=12.55^{\circ}, \operatorname{Re}=4.20 \times 10^{6}\right)$.

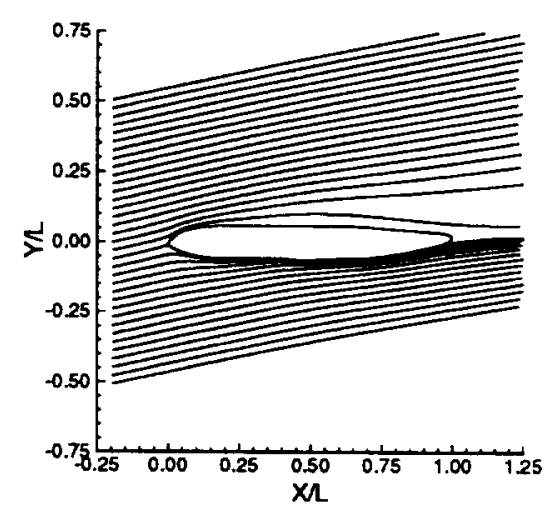

a) full-span

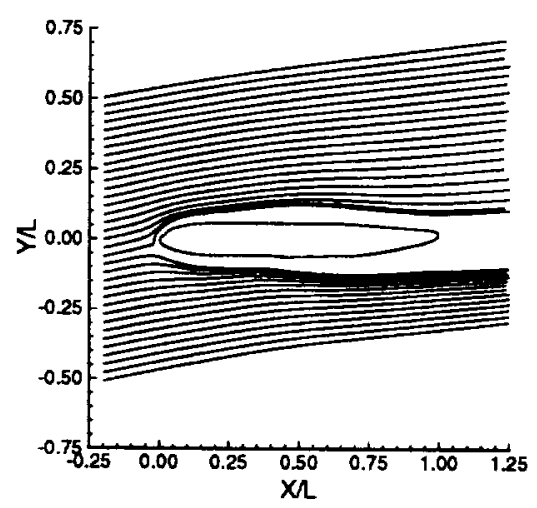

b) semi-span: $\mathrm{C}_{\mu}=0.000$

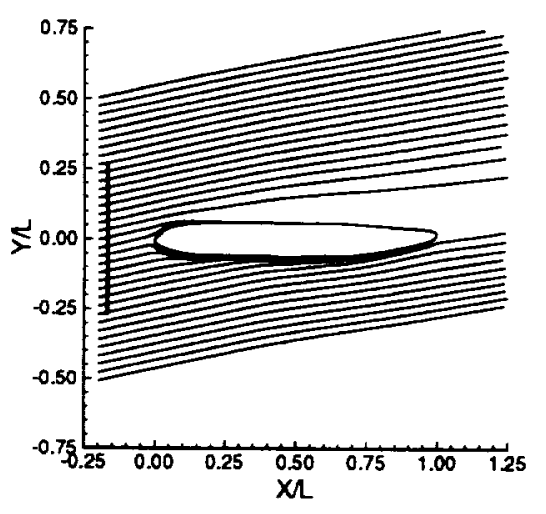

c) semi-span: $\mathrm{C}_{\mu}=1.027$

Figure 16: Influence of upstream blowing on root plane streamline patterns $\left(\mathrm{M}_{\infty}=0.20\right.$, $\alpha=12.55^{\circ}, \operatorname{Re}=4.20 \times 10^{6}$ ). 

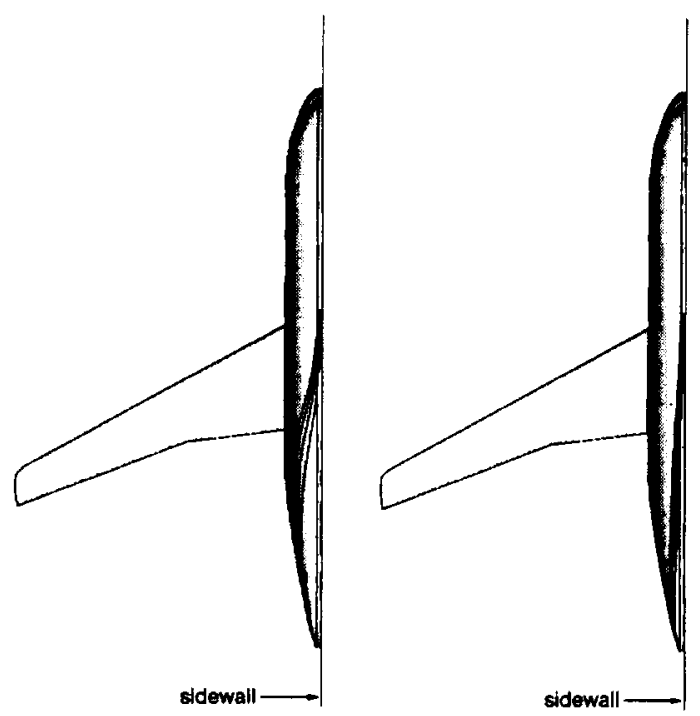
a) $\mathrm{C}_{\mu}=0.000$
b) $\mathrm{C}_{\mu}=1.027$

Figure 17: Influence of upstream blowing on semi-span upper fuselage streamline patterns $\left(\mathrm{M}_{\infty}=0.20, \alpha=12.55^{\circ}\right.$, $\operatorname{Re}=4.20 \times 10^{6}$ ).
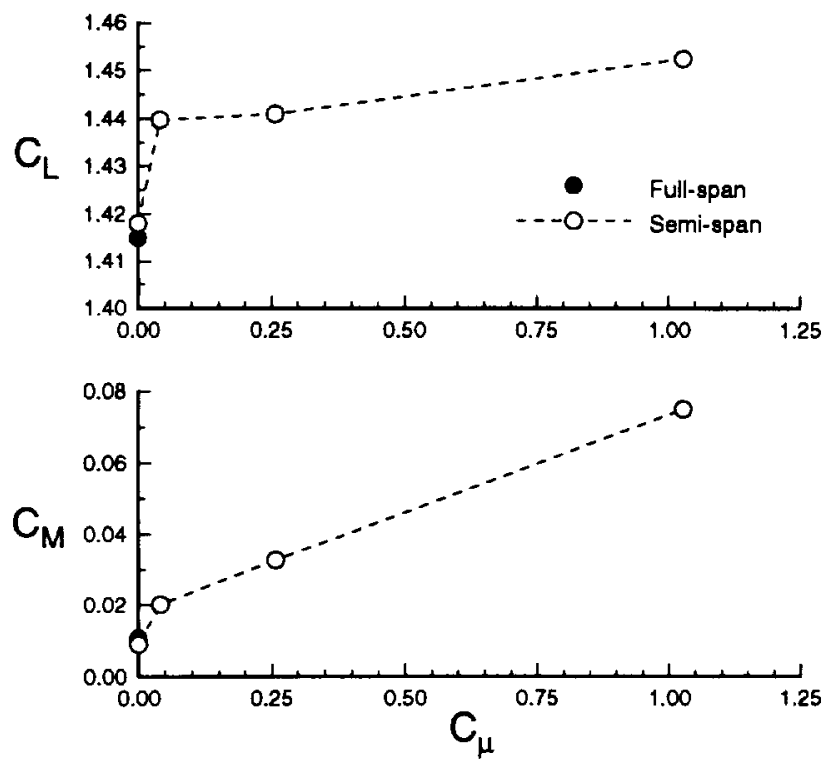

Figure 18: Influence of upstream blowing on semi-span lift and pitching moment coefficients $\left(\mathrm{M}_{\infty}=0.20, \alpha=12.55^{\circ}\right.$, $\operatorname{Re}=4.20 \times 10^{6}$ ).

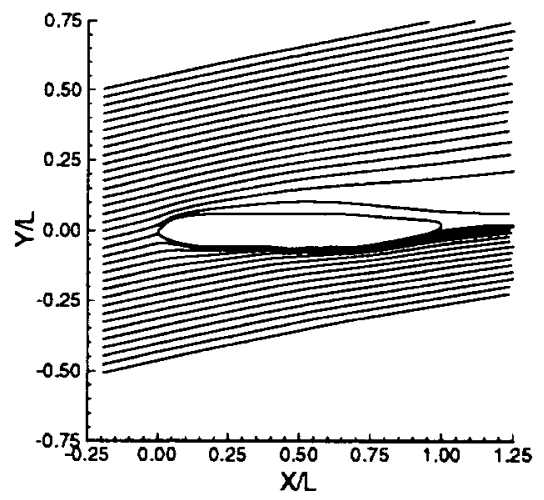

a) full-span

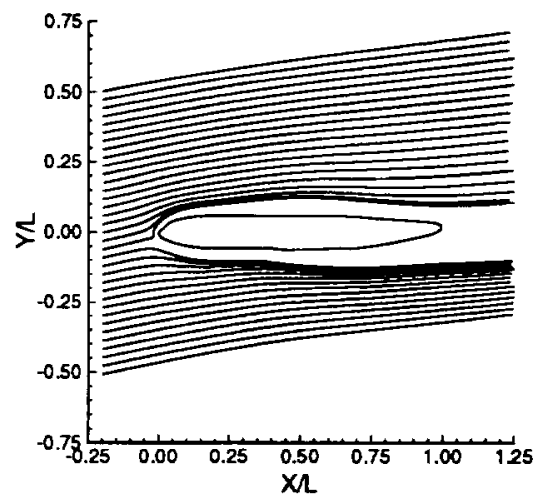

b) semi-span: $C_{q}=0.000$

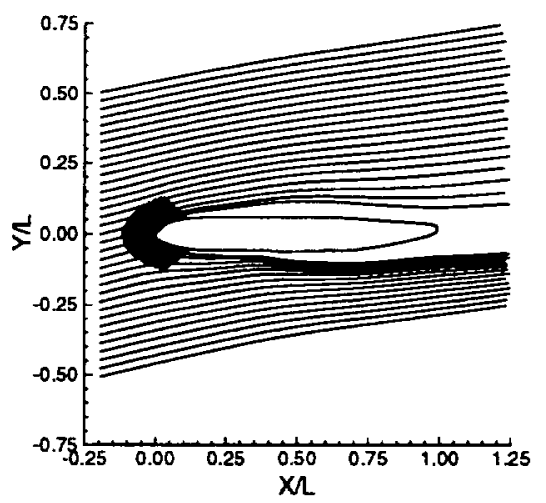

c) semi-span: $C_{q}(1)=-.020$

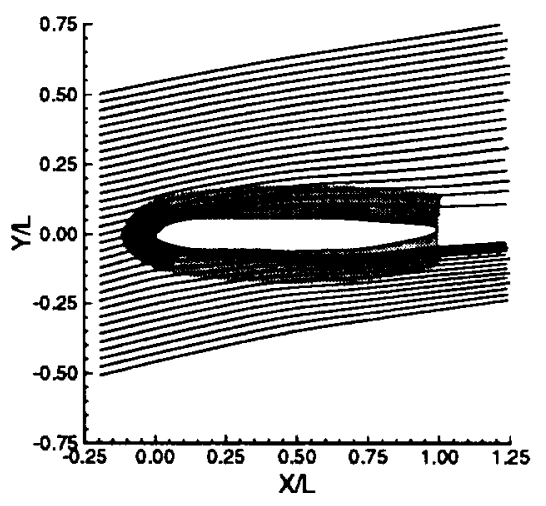

d) semi-span: $C_{\mathbf{q}}(1)=-.020, C_{\mathbf{q}}(2)=-.005$

Figure 19: Influence of sidewall suction on root plane streamline patterns $\left(\mathrm{M}_{\infty}=0.20\right.$, $\left.\alpha=12.55^{\circ}, \operatorname{Re}=4.20 \times 10^{6}\right)$. 

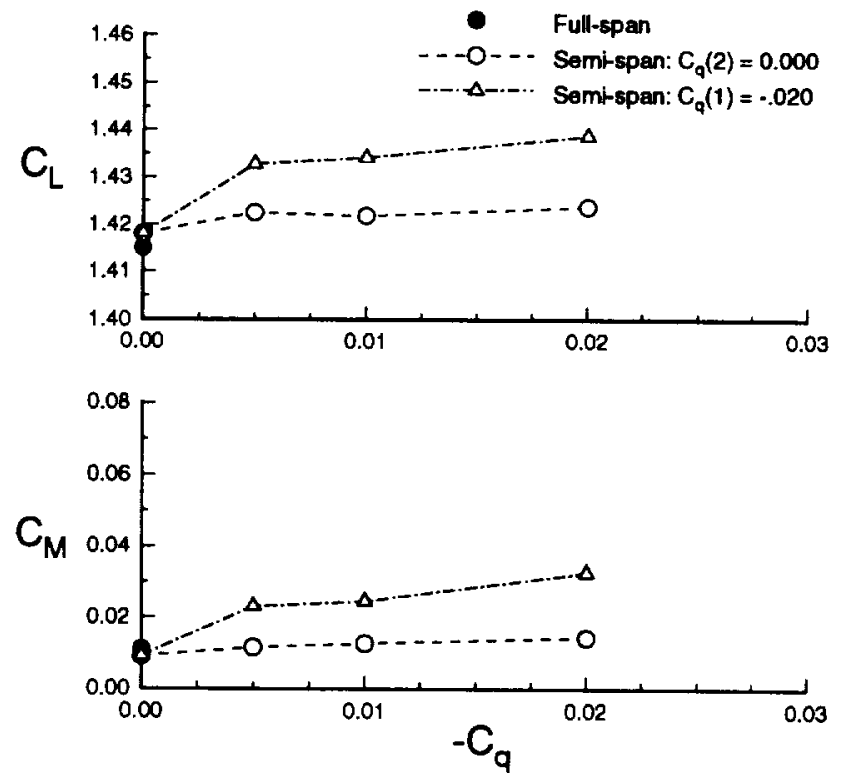

Figure 20: Influence of sidewall suction on semi-span lift and pitching moment coefficients $\left(\mathrm{M}_{\infty}=0.20, \alpha=12.55^{\circ}\right.$, $\left.\operatorname{Re}=4.20 \times 10^{6}\right)$. 
